\title{
A GUERRA DAS TUBAÍNAS: ESTRATÉGIAS COMPETITIVAS DAS INDÚSTRIAS DE REFRIGERANTES POPULARES
}

\author{
TUBAÍNA WARS: COMPETITIVE STRATEGIES \\ OF BRAZILIAN POP SODA INDUSTRIES
}

\author{
Luciel Henrique de Oliveira ${ }^{1}$ \\ Fábio Eiki Ueno ${ }^{2}$
}

\begin{abstract}
RESUMO: Tubaína é o nome de um refrigerante sabor "tutti-frutti", produzido por indústrias nacionais, com muitas variações regionais. São refrigerantes populares, muito doces, com preço mais baixo e marca local, conhecidos pelo nome genérico de tubaínas. Este trabalho tem o objetivo de descrever a importância econômica da indústria brasileira de refrigerantes, sob a ótica dos pequenos e médios fabricantes de produtos populares do Estado de São Paulo, destacando alguns casos particulares. Quais as estratégias usadas pelas indústrias de tubaínas para enfrentar as grandes empresas do setor? Como estas empresas conseguem sobreviver e crescer em um mercado tão competitivo? A pesquisa teve três objetivos: (1) conhecer e compreender a indústria de refrigerantes populares, destacando a participação das indústrias regionais; (2) levantar das indústrias de refrigerantes populares do Estado de São Paulo, destacando os casos mais relevantes; (3) analisar os casos de destaque, relacionando-os com as teorias de estratégia previstas. Verificou-se que a principal estratégia das pequenas e médias empresas do setor é priorizar e focar suas forças nos mercados regionais em que suas fábricas se localizam. Além disso, investem em verticalização da produção, em equipamentos modernos semelhantes aos utilizados pelas grandes empresas, e em inovação, para reduzir custos e obter uma vantagem competitiva frente aos concorrentes. Procuram sempre seguir as tendências de sucesso impostas pelos grandes players do mercado. Aliando preços mais baixos a um produto de qualidade e à tradição local de se consumir esses refrigerantes, estas empresas conseguem competir e incomodar as grandes indústrias do setor.
\end{abstract}

Palavras-Chave: Refrigerantes, consumo popular, estratégia, competitividade, tubaínas.

ABSTRACT: Tubaína is the generic name of a tutti-frutti flavored soft drink, produced by Brazilian industries, with many regional variations. These soft drinks are generally popular, very sweet, with lower price and local brand. This research aimed to describe the economic importance of the Brazilian soft drinks, from the point of view of small and medium manufacturers. What strategies used by these industries to face the big companies competition? How can these companies survive and grow in such a competitive market? The study had three objectives: (1) know and understand the popular soft drink industry, highlighting the participation of regional industries, (2) raise the popular soft drink industries of São Paulo State, highlighting the most relevant cases, (3) analyze prominent cases, relating them to theories of strategy envisaged. We found that the main strategy of small and mid-sized companies is to prioritize and focus their strength in regional markets where their factories are located. Producers

\footnotetext{
${ }^{1}$ Doutor em Administração, com Pós-Doutorado em Gestão Estratégica da Inovação, Professor da EAESP - Fundação Getúlio Vargas/SP e do Mestrado em Desenvolvimento Sustentável e Qualidade de Vida - UNIFAE, São João da Boa Vista/SP. E-mail: luciel@uol.com.br

${ }^{2}$ Graduado em Administração na EAESP - Fundação Getúlio Vargas/SP. E-mail: fabioeiki@ gmail.com 
invest in production vertical integration, modern equipment similar to those used by large enterprises, and innovation to reduce costs and gain a competitive advantage. Always they try to follow the trends set by big players hit the market. Combining the lower prices and a quality product to the local tradition of consuming these soft drinks, these companies can compete and annoy the major sector's industries.

Keywords: Soft drinks, popular consumption, strategy, competitiveness, Tubaína.

\section{Introdução}

O verbete "tubaína" não consta nos dicionários Aurélio e Michaellis. Tubaína é o nome de um refrigerante sabor "tuttifrutti", produzido por indústrias nacionais, com muitas variações regionais. Segundo Penteado, citado em matéria da Revista Recall (2003), o nome "tubaína" foi criado pelo italiano Pedro Pattini e utilizado para batizar, inicialmente as balas por ele fabricadas no início de sua atividade empresarial no Brasil. Na década de 1940, quando passou a produzir refrigerantes, estes herdaram o nome. Hoje, a Ferráspari utiliza em seus rótulos "Tubaína" ou "Turbaína", marcas registradas no INPI (Instituto Nacional da Propriedade Industrial).

Tubaína é marca registrada da empresa Ferráspari, de Jundiaí (SP), e se popularizou graças aos concorrentes que, ainda nas décadas de 1940 e 1950, pediram autorização ao proprietário da marca para utilizarem o sufixo do nome em seus produtos. Com isso, surgiram a Taubaína, a Itubaína e algumas outras. Segundo
Penteado, citado em matéria da Revista Recall (2003) a Ferráspari optou por permitir que empresas maiores utilizassem esta denominação para promover, indiretamente, o seu produto, gerando o neologismo, que significa refrigerante popular, de baixo preço, de sabor mais adocicado, geralmente comercializado em garrafas de cerveja ou em garrafas PET. A popularização do nome deve-se à metonímia, fenômeno lingüístico que se dá quando a marca assume o nome do objeto.

Em geral, os refrigerantes populares, muito doces, com preço mais baixo e marca local são conhecidos pelo nome genérico de tubaínas. Enquanto alguns fabricantes até tiram proveito do nome, outros vêem o termo como um sinônimo pejorativo e não querem ser associado a ele. Em alguns pontos de venda, uma garrafa de tubaína chega a custar menos do que uma garrafa de água. Atualmente, uma das mais conhecidas é o refrigerante "Itubaína", um produto da Schincariol.

Os pequenos e médios fabricantes de refrigerantes usam a estratégia de conquistar os consumidores pelos seus 
preços populares, e alguns têm conseguido roubar importantes fatias do mercado de multinacionais. Na última década, além de oferecer preços atrativos, estas empresas também têm investido em qualidade para ampliar vendas e mudar a imagem dos seus produtos, através da diversificação de estratégias de promoção e venda, de embalagens, da produção de marcas próprias para redes de hipermercados e até mesmo conquistando mercado externo, investindo em novos sabores e fórmulas.

Grandes mudanças no mercado de refrigerantes nacional ocorreram na década de 1990, dentre as quais se podem destacar a intensificação das vendas dos refrigerantes de marcas menores, que com a implantação do plano real, obtiveram um aumento significativo de suas vendas. Após anos de superação de grandes marcas, como a Coca-Cola, algumas alterações no cenário dos refrigerantes, como o aumento do poder aquisitivo da população, as embalagens PET, entre outras, contribuíram para que as tubaínas aumentassem sua participação no mercado, visto que a fidelidade a marca não é mais um fator determinante para compra. É interessante observar que foi a própria Coca-Cola a precursora do vasilhame PET (MIRANDA, 2001).

O refrigerante é um bem extremamente dependente do poder aquisitivo da população. $\mathrm{O}$ consumo de refrigerantes no Brasil é de 14.339 bilhões de litros (ABIR, 2009). Apesar do crescimento das tubaínas, a Coca-Cola ainda detém o domínio deste mercado com uma participação bem superior a de seus concorrentes. A AmBev aparece em segundo lugar. Esta estratégia de união de marcas como Brahma e Antarctica, visava reduzir a diferença existente entre a Cocacola no segmento de refrigerantes, fato que não se consolidou. Segundo a ABIR (2009), em 2009 a Cola-Cola teve 56,6\% de participação de mercado, a AmBev $17,8 \%$, Schincariol $4,0 \%$ e as outras marcas somaram 21,6\%, mostrando o crescimento e agressividade das pequenas e médias empresas do setor.

Este trabalho é um estudo exploratório, com o objetivo geral de descrever a situação da indústria brasileira de refrigerantes, sob a ótica dos pequenos e médios fabricantes de produtos populares do Estado de São Paulo. Quais as estratégias usadas pelas indústrias de tubaínas para enfrentar as grandes empresas do setor? Como estas empresas conseguem sobreviver e crescer em um mercado tão competitivo? Esse estudo procura descrever a importância econômica da indústria de refrigerantes, a sua cadeia produtiva, analisar as estratégias desenvolvidas pelas pequenas e médias 
indústrias de refrigerantes, e destacar casos particulares de indústrias localizadas no interior do estado de São Paulo.

\section{Referencial teórico}

A Indústria brasileira de refrigerantes caracteriza-se pela sua representação no segmento de bebidas no mercado nacional. De acordo com o Panorama Setorial Gazeta Mercantil (1998, p.5), “a indústria brasileira de refrigerantes é uma das mais avançadas e maiores do mundo. É dotada de uma estrutura tecnológica que atende praticamente sozinha a demanda do mercado". Demanda esta, que se caracterizou, nos últimos anos, pelo surgimento das tubaínas e que levou as grandes companhias a intensificarem seu marketing, visando alcançar diferentes categorias de consumidores e tornando a abrangência de mercado um fator essencial. Conforme Kotler (2000), a Coca-Cola procura colocar seu refrigerante facilmente ao alcance de todos, utilizando o marketing de massa, por meio do qual a empresa oferece um produto e até mesmo serviços de forma padronizada a todo mercado.

Já empresas menores, que aumentaram significativamente sua participação no mercado, enfocam suas estratégias em regiões específicas visando distribuir e vender os refrigerantes nestas áreas principalmente. Kotler (2000, p.39), define estas empresas como aquelas que praticam o marketing de segmento: "São empresas que projetam seus produtos e serviços para um ou mais segmentos específicos em vez de para todo mercado".

Apesar de grandes empresas como Coca-Cola, desfrutarem de um benefício importantíssimo - que é a marca - as indústrias de refrigerantes não concorrem somente entre elas. Bebidas como, chá gelado, isotônicos, sucos entre outros intensificam ainda mais a concorrência. Para compreender a análise da concorrência é importante demonstrar quais os concorrentes que deverão ser examinados. Os concorrentes importantes já existentes e que apresentam um crescimento significativo devem ser analisados, bem como aqueles que ainda pode vir a integrar este mercado. Estes últimos são denominados, segundo Porter (1986), como concorrentes potenciais, cuja previsão é uma tarefa difícil.

\subsection{Estratégias Genéricas de Porter}

Porter (1986 e 1990) identificou e definiu três estratégias genéricas: liderança em custo, diferenciação e foco. A "liderança em custo" enfatiza a produção padronizada pelo menor custo possível por unidade para atender o público com demanda sensível a preço. "Diferenciação" 
refere-se à produção visando atender uma demanda que é pouco sensível a preço; e "foco" significa atender os desejos de um grupo particular que ocupa uma parte pequena da demanda de toda a indústria. A opção por uma estratégia genérica de liderança em custos, assim como uma estratégia de diferenciação visa atender toda a indústria enquanto uma estratégia de foco visa atender apenas uma parte do mercado. "As estratégias genéricas também implicam arranjos organizacionais diferentes, procedimentos de controle e sistemas criativos" (Porter, 1986, p. 54).

\subsection{Estratégias para atuação em mercados de baixa renda}

A literatura especializada revela algumas inovações realizadas pelas empresas que atuam no mercado popular, ou de baixa renda. As inovações foram compiladas em cinco categorias e em 25 subcategorias, sistematizadas por Zancul (2005). Estas subcategorias (gerais para toda indústria) serão utilizadas para analisar as estratégias utilizadas pelas indústrias de refrigerantes populares, seja formalmente ou não, conscientemente ou não.

\subsubsection{Categoria 1 - Modelo de negócios para mercados de baixa renda}

1) Modelo de negócios específico para baixa renda versus atuação segmentada - Prahalad e Lieberthal (1998) enfatizam que as empresas devem constituir modelos de negócios distintos para competir em mercados populares. Algumas empresas seguem esse pressuposto. É o caso da Casas Bahia (BLECHER, 2004a). Na prática outras empresas mantêm uma atuação segmentada com sucesso. A Sorvetes Alaska atua em dois segmentos: sobremesas sofisticadas para restaurantes e sorvetes baratos para lojas populares (NOGUEIRA et al., 2003). A L'oréal atua primordialmente em produtos de luxo, mas possui uma divisão de produtos de massa, chamada L'oréal Garnier (PINSKI et al., 2004). A constituição de uma operação independente para mercados populares ou a segmentação são então duas possíveis opções estratégicas.

2) Baixo capital investido versus

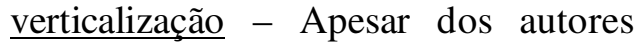
enfatizarem também a necessidade de baixo capital investido nesse mercado (PRAHALAD \& LIEBERTHAL, 1998; PRAHALAD \& HART, 2002), algumas empresas verticalizaram alguns aspectos de sua operação para 
reduzir custos ou para viabilizar a estratégia. Para viabilizar a distribuição em pequenas redes de supermercado de bairro a Massas Scala optou por realizar a distribuição com frota própria (MARINO et al., 2003). A Casas Bahia fabrica grande parte dos móveis vendidos em suas lojas, possui frota própria para a distribuição dos produtos e possui uma grande equipe de analistas de crédito com cerca de novecentas pessoas (BLECHER, 2004a). Todas essas atividades são geralmente terceirizadas em outras redes de varejo.

3) Alta eficiência de capital - A alta eficiência do capital investido também é citada na literatura como um dos fatores que contribui para a redução dos custos unitários (PRAHALAD \& LIEBERTHAL, 1998). Nesse sentido, a Sorvetes Alaska utiliza equipamentos arrendados de fornecedores de máquinas (NOGUEIRA et al. 2003) e a Gol adota um procedimento diário de manutenção que reduz o tempo total de manutenção e garante maior aproveitamento da utilização das aeronaves (BLECHER, 2004b).

4) Foco em ganhos de escala e produção para terceiros - Para garantir maior volume de produção e ganhos de escala algumas empresas fabricam produtos para terceiros. A Massas Scala fabrica macarrão para concorrentes para otimizar a ocupação de seus equipamentos (MARINO et al., 2003). A Latina Eletrodomésticos produz máquinas de lavar com a marca própria de redes varejistas.

5) Foco em redução de custo - Todas as empresas analisadas enfatizam a preocupação em redução de custos. Por exemplo, a estrutura organizacional é bastante enxuta na Refrigerantes Convenção (GARCEZ et al., 2004) e na Massas Scala (MARINO et al., 2003). Essa característica também se observa na Latina Eletrodomésticos.

\subsubsection{Categoria 2 - Processo de} desenvolvimento de produtos populares

6) Entendimento claro do consumidor de baixa renda - Nessa categoria uma das maiores dificuldades é a "distância" existente entre os funcionários que atuam no desenvolvimento de produtos nas empresas e o consumidor de baixa renda (BLECHER \& TEIXEIRA, 2003). Para superar essa "distância" a Unilever contratou a Fundação Getúlio Vargas para realizar uma pesquisa sobre clientes de baixa renda (FGV, 2003). A Latina mantém uma base de dados de clientes com grande quantidade de registros. A fim de 
incentivar a participação dos consumidores, a Latina oferece extensão gratuita de garantia para os clientes que se cadastrarem em sua base de dados.

7) Utilização intensiva do conceito de plataformas e de produtos derivados O conceito de plataforma é baseado em alta comunalidade de partes entre produtos de uma família e resulta em ganhos de escala mesmo com a oferta de maior variedade de produtos ao mercado. A Latina desenvolve plataformas de lavadoras de roupa que são então vendidas em diversos modelos derivados. Na L'oréal Garnier, o desenvolvimento de novas colorações consiste basicamente na substituição do tonalizante em uma fórmula base (PINSKI et al., 2004).

8) Testes realizados por funcionários - No Brasil, os funcionários de nível operacional nas empresas são típicos clientes de classe C. Considerando isso, na Sorvetes Alaska os novos sabores de sorvetes são testados pelos próprios funcionários (NOGUEIRA et al. 2003). O procedimento também é realizado para lavadoras de roupa na Latina Eletrodomésticos.

9) Foco em baixo custo de desenvolvimento - Na Massas Scala, o desenvolvimento de produtos é realizado por uma equipe pequena que não possui dedicação exclusiva ao desenvolvimento (MARINO et al., 2003). A Escapamentos Mastra enfatiza alta produtividade dos engenheiros (em número de projetos) e o reaproveitamento de informações de projetos anteriores para reduzir o tempo de desenvolvimento (MARSON et al. 2003).

10) Emprego de tecnologias e de processos comprovados (empresa não faz $\mathrm{P} \& \mathrm{D}$ avançado) - Nenhuma das empresas analisadas realiza pesquisa avançada de novas tecnologias para o desenvolvimento de produtos populares.

11) Atuação como seguidor rápido (fast follower) - A atuação como seguidor rápido possibilita que as empresas invistam em uma inovação quando a probabilidade de sucesso é maior por já ter sido testada em outra empresa. A Refrigerantes Convenção procura seguir rapidamente o posicionamento das empresas líderes na introdução de novos processos de produção e de novas embalagens, como foi o caso da embalagem PET (GARCEZ et al., 2004). A Mastra Escapamentos faz engenharia reversa de produtos já existentes (MARSON et al. 2003). 
2.2.3. Categoria 3 - Características dos produtos populares

12) Inovação em embalagens - A inovação em embalagens visa adequar a exposição do produto "refrigerantes populares" ao mercado consumidor e reduzir custos. A fim de dar uma imagem mais nobre ao seu produto, a Massas Scala desenvolveu novas embalagens semelhantes às embalagens de produtos importados (MARINO et al., 2003) enquanto que a Refrigerantes Convenção reduziu o peso próprio da embalagem para economizar matériaprima (GARCEZ et al., 2004).

13) Inovações para redução de preços - As principais inovações realizadas para reduzir o preço dos produtos são a redução de atributos e a substituição de materiais caros por mais baratos. Nesse sentido, a Gol Linhas Aéreas eliminou as refeições a bordo de seus aviões (BLECHER, 2004b), as lavadoras de roupa da Latina não possuem a função de centrifugação e Whirlpool substituiu o aço inox pelo plástico em lavadoras (BLECHER \& TEIXEIRA, 2003).

14) Produtos com alta qualidade - As empresas analisadas enfatizam que a qualidade dos produtos não pode ser negligenciada apesar do baixo preço de venda. Produtos robustos para enfrentar condições mais severas - Os produtos populares precisam ser projetados considerando que os clientes de baixa renda muitas vezes submetem os produtos a condições de uso diferenciadas, como uso mais intenso (as famílias são maiores) e operação adversa (ruas esburacadas, exposição a intempéries, entre outros fatores).

15) Produtos bonitos e que atribuem status - A Latina Eletrodomésticos considera que os clientes de baixa renda dão grande importância à beleza e ao status atribuído pelos produtos e por isso investe no design de produtos semelhantes aos produtos mais caros no mercado.

16) Produtos novos não adaptados de produtos sofisticados de outros mercados - $\mathrm{O}$ desenvolvimento de produtos populares geralmente não funciona na adaptação de produtos mais sofisticados, pois os preços continuam altos (PRAHALAD \& HART, 2002). Por isso, algumas empresas estão desenvolvendo produtos específicos para o mercado de baixa renda, como a L'oréal Garnier (PINSKI et al., 2004) e a Whirlpool (MARGOLIS, 2004).

17) Produtos fáceis de operar - A facilidade de operação aumenta a satisfação dos usuários e minimiza o potencial de quebras por uso 
inadequado. Nesse sentido, a nova lavadora popular da Whirlpool possui botões mecânicos e instruções de operação mais simples do que as lavadoras mais completas (BLECHER \& TEIXEIRA, 2003).

18) Inovações para criar condições de compra acessíveis - Para viabilizar a compra de móveis e de eletrodomésticos, a Casas Bahia possibilita que o cliente divida o pagamento de suas compras em até 18 meses (BLECHER, 2004a)

\subsubsection{Categoria 4 - Processos de produção}

19) Inovação em processos com foco em redução de custos - A inovação em processos pode levar a reduções significativas de custo. É o caso de uma empresa chinesa avaliada por (PRAHALAD \& LIEBERTHAL, 1998) que encontrou uma forma de produzir detergentes com processos que custam um quinto dos processos convencionais.

20) Equipamentos modernos e com alta tecnologia - Equipamentos novos proporcionam maior produtividade $\mathrm{e}$ menores custos. Por isso, a Refrigerantes Convenção utiliza equipamentos automatizados de última geração, semelhantes aos equipamentos utilizados por empresas líderes como a AmBev (GARCEZ et al., 2004). A Biscoitos Festivo também procura utilizar equipamentos modernos para ganhar eficiência produtiva (NASCIMENTO \& YU, 2003).

21) Redução do número de fornecedores e utilização de matéria-prima nacional Trata-se de medidas tradicionais utilizadas nas empresas para reduzir o custo de suprimentos. A Biscoitos Festivo procura ter apenas um fornecedor para cada tipo de matériaprima e utilizar ingredientes nacionais e não importados (NASCIMENTO \& YU, 2003).

\subsubsection{Categoria 5 - Processos de vendas, distribuição e pós-venda de produtos populares}

22) Distribuição em mercados específicos $\underline{\text { (regiões ou cidades) }}$ - Esse fator possibilita melhor adequação do produto e de seu preço às necessidades e ao poder aquisitivo dos consumidores. O sabão em pó Ala, da Unilever, é comercializado somente nas regiões Norte e Nordeste do Brasil (UNILEVER, 2009).

23) Soluções logísticas alternativas - Essa medida visa redução dos custos de frete. Um exemplo é a realização de parcerias para dividir as despesas com 
frete de retorno, realizada pela Refrigerantes Convenção no transporte inter-plantas (GARCEZ et al., 2004).

24) Mercados de exportação com características análogas ao mercado brasileiro - Além do Brasil, os produtos da Latina Eletrodomésticos são vendidos em nove países com características análogas ao mercado brasileiro.

25) Canais de venda alternativos com menor poder de barganha - Os canais de venda tradicionais, como grandes redes varejistas, pressionam a margem dos fornecedores em função do alto volume que comercializam. Por isso, a Massas Scala passou a direcionar seus produtos para supermercados de bairro (MARINO et al., 2003) e a Refrigerantes Convenção está incrementando as suas vendas em pequenos mercados, bares e restaurantes (GARCEZ et al., 2004). Outra possibilidade discutida é o uso da Internet como canal de vendas de produtos mais baratos.

\subsection{Mercado de Refrigerantes - conceitos e definições}

A indústria de refrigerantes demonstra superioridade das grandes marcas, que tem forte participação no mercado e um sólido desempenho por todo o país. Todavia, nos últimos anos, percebe-se que estas vêm sofrendo com a concorrência das marcas regionais, cujo desempenho tem obrigado as grandes marcas a rever suas estratégias. Se antes as pequenas e médias empresas não eram alvo de atenção das grandes, com a proliferação dessas marcas e seu desempenho conjunto constantemente notável, as grandes marcas foram obrigadas a dedicar mais tempo e trabalho para conter o avanço das menores. Apesar de sozinhas as pequenas e médias marcas de refrigerantes não terem um desempenho expressivo em âmbito nacional, o apelo que tais empresas têm junto ao público local, a tradição que carregam consigo na região em que atuam levam-nas a conseguir uma considerável fatia dos consumidores, sobretudo nas classes mais baixas. Assim, ao somar todas essas indústrias menores e locais, tem-se uma importante parcela do mercado consumidor, que concorre com as grandes marcas.

Como exemplo, há marcas como o guaraná Jesus, unanimidade no Maranhão, que, devido à sua importância no estado e relevância no volume de vendas, foi adquirido pela Coca Cola. Há também o exemplo da empresa pernambucana Frevo Brasil, que, segundo Machado, Oliveira e Filho (2004) explora o regionalismo da marca e a forte identificação com o povo 
nordestino, e procura competir por preços, fabricando produtos de qualidade a baixos custos, para se diferenciar no mercado.

Segundo Santos e Azevedo (2000), um fator que proporcionou a descentralização das indústrias de refrigerante e a proliferação de marcas menores foi exatamente o surgimento das garrafas PET (polietileno tereftalato). Com o advento das garrafas PET, foram reduzidas as barreiras de entrada no mercado, já que muito se reduziu os custos de produção. Por fim, há também fora do Brasil empresas que conseguem sobreviver e competir com os grandes players do mercado, adotando diferentes estratégias. Conforme estudo de Bonel e Rocco (2007), na Itália, a empresa San Benedetto trabalha com o conceito de coopetition, trabalhando com a cooperação de empresas parceiras para conseguir competir num mercado dominado por empresas como Coca Cola, Schweppes e Pepsi.

\section{Procedimentos Metodológicos}

O trabalho analisou a indústria de refrigerantes no Brasil, através das estratégias Genéricas de Porter, e também das estratégias para atuação em mercados de baixa renda (cinco categorias e 25 subcategorias); destacando o crescimento e a estratégia dos refrigerantes populares (tubaínas), e enfocando o caso específico de indústrias localizadas no interior de São Paulo. O trabalho é descritivo, a partir de pesquisas bibliográficas ligados à estratégia empresarial e marketing.

Inicialmente fez-se uma pesquisa e uma busca por dados que expusessem a importância econômica da indústria de refrigerantes, com destaque para os refrigerantes populares. Essa pesquisa iniciou-se, de fato, alguns meses antes com a elaboração do projeto de pesquisa apresentado em julho/agosto, já que desde então ela já era necessária.

$\mathrm{Na}$ segunda fase foi feito um levantamento das principais marcas populares de refrigerantes produzidos no estado de São Paulo, descrevendo sua história e aspectos competitivos, a partir de dados secundários, sobretudo sites e reportagens encontrados na internet. Após fazer o levantamento das pequenas e médias empresas do setor no estado de São Paulo, foram selecionados os casos julgados como os mais interessantes para o estudo em questão. Fatores como a tradição, um forte apelo regional, a disponibilidade de informações em sites na internet e reportagens e mesmo a facilidade e conveniência de se conseguir visitas e entrevistas, foram determinantes para que esses casos fossem selecionados para dar prosseguimento ao estudo. 
$\mathrm{Na}$ terceira e última fase procurou-se destacar alguns dos casos e estuda-los mais a fundo, a partir dos dados conseguidos com entrevistas e visitas, procurando encontrar exemplos de boas práticas competitivas no mercado de refrigerantes populares. A partir dos materiais coletados, procurou-se comparar as estratégias percebidas a partir das entrevistas e verificar se elas estão de acordo com as teorias de estratégia consideradas no referencial teórico.

Foram feitos contatos - através de email, cartas enviadas pelo correio e também ligações telefônicas - com os empresários responsáveis pelas empresas abordadas. Num primeiro momento foram enviadas cartas a aproximadamente dez empresas, e não houve nenhuma resposta. A partir disso foram feitas ligações telefônicas.

Trata-se de uma pesquisa exploratória, pois pode prover novas idéias e descobertas sobre o tema. De acordo com a taxonomia de Vergara (1998), essa pesquisa pode ser classificada quanto aos fins, como sendo exploratória e quanto aos meios de investigação, como pesquisa de campo - por meio do método de estudo de caso (Yin, 2001) e bibliográfica. As questões da pesquisa mostram que a estratégia mais adequada para este projeto é um estudo de caso, que trata de questões do tipo "como" e "por que".

Yin (2001) define o estudo de caso como o método que examina o fenômeno de interesse em seu ambiente natural, pela aplicação de diversas metodologias de coleta de dados, visando obter informações de múltiplas entidades. A análise dos casos selecionados feita através da observação direta nas indústrias e de entrevistas desenvolvidas diretamente com os executivos das empresas selecionadas (pesquisa de campo). Os resultados da entrevistas e análises de documentos dos casos selecionados foram tratados por análise de conteúdo. O método da análise de conteúdo é uma ferramenta para a compreensão da construção de significado que os atores sociais exteriorizam no discurso, Bardin (1979).

\section{Resultados e Discussão}

\subsection{Panorama das indústrias de refrigerante no Brasil}

A indústria brasileira de refrigerantes teve como determinante básico para seu sucesso na década de 1090, a implantação do Plano Real em 1994, cujo programa de estabilização da economia permitiu um aumento da capacidade de compra do público em geral. Como o refrigerante é um bem supérfluo não tido como essencial, suas vendas dependem em muito do poder 
aquisitivo da população. A estabilização econômica do país em 1994 permitiu que as vendas de refrigerante crescessem em uma média histórica. De acordo com o Panorama Setorial Gazeta Mercantil (1998), o dinamismo da indústria de refrigerantes depende diretamente do nível do poder aquisitivo da população. Após a implantação do Plano Real, o consumo de refrigerantes cresceu $41,93 \%$. O quadro 1 sintetiza dados sobre vendas, participação de mercado e consumo de matéria prima do setor, nos anos de 2002 e 2003, e permite perceber a importância econômica do setor. Segundo a ABIR (2002), existem cerca de 700 fábricas de refrigerantes no país, produzindo 3.500 marcas diferentes, distribuídas em cerca de um milhão de pontos de venda, gerando 60 mil empregos diretos e 520 mil indiretos.

No cadastro da Associação Brasileira da Indústria de Refrigerantes e de Bebidas não Alcoólicas (ABIR), existem registradas 40 indústrias de refrigerantes independentes. Já a Associação dos Fabricantes de Bebidas do Brasil (AFREBRAS) contra com aproximadamente 130 associadas. Enquanto na década de 1980 as empresas nem entravam nas estatísticas, em 2001, todas juntas movimentaram cerca de $\mathrm{R} \$$ 3,5 bilhões e, em 2003 já conquistavam $32 \%$ deste mercado no Brasil, segundo estimativas de Menezes, diretor da ABIR, citado pela Revista Recall (2003).

Quadro 1: Participação de mercado e consumo de matéria prima no setor de refrigerantes

\begin{tabular}{|c|l|}
\hline $\begin{array}{c}\text { Vendas e } \\
\text { participação de } \\
\text { mercado }\end{array}$ & $\begin{array}{l}\text { Venda de refrigerantes em 2008: 14,148 bilhões de litros } \\
\text { Venda de refrigerantes em 2009: 14,339 bilhões de litros (aumento de 5,44\% em } \\
\text { relação a 2001) }\end{array}$ \\
\hline $\begin{array}{c}\text { Consumo anual } \\
\text { de matérias- } \\
\text { primas no setor }\end{array}$ & $\begin{array}{l}\text { Açúcar: 1,196 milhão toneladas } \\
\text { Laranja: } 120 \text { mil toneladas (suco pronto para beber) } \\
\text { Uva: } 12 \text { mil toneladas (suco pronto para beber) } \\
\text { Limão: } 9 \text { mil toneladas (suco pronto para beber) }\end{array}$ \\
\hline $\begin{array}{c}\text { Participação } \\
\text { Mercado de } \\
\text { Refrigerantes }\end{array}$ & $\begin{array}{l}\text { Coca-Cola ................ 56,6\% } \\
\text { AmBev.................... 17,8\% }\end{array}$ \\
\hline
\end{tabular}

Fonte: ABIR (2009)

A estabilização econômica também possibilitou que um grande número de pequenas empresas, conhecidas como "tubaineiros", crescesse significativamente concorrendo regionalmente com as grandes empresas. Este impulso deve-se também à vulgarização do uso das embalagens PET, as quais por terem custos menores e serem descartáveis possibilitaram que estas empresas vendessem refrigerantes a um preço bem inferior. Antes da possibilidade de uso deste tipo embalagem, a expansão 
de marcas menores era limitada pela dificuldade de trabalhar com a logística de embalagens retornáveis.

$\mathrm{O}$ desenvolvimento dessas empresas menores e regionais possibilitou um aumento significativo na variedade de refrigerantes. Atualmente é possível encontrar nos postos de vendas não apenas os chamados refrigerantes tradicionais, mas um grande número de marca e sabores que, em sua maioria, apresentam qualidade bem inferior.

Segundo o Panorama Setorial Gazeta Mercantil (1998), através de dados obtidos pela Associação Brasileira de Refrigerantes (ABIR), as classes que apresentam maior poder aquisitivo são as principais consumidoras de refrigerantes. As classes C e D representam uma fatia significante e é vista como a faixa mais promissora pelas indústrias para promover um aumento nas vendas, visto que a fidelidade à marca não é mais uma característica forte. Por último encontramse os brasileiros mais pobres, dentre os quais o consumo de refrigerantes é pequeno e prevalece a venda dos refrigerantes de segunda linha, as popularmente chamadas "tubaínas". A maior preferência dos consumidores é pelas colas, segmento em que predominam marcas como Coca-Cola principalmente e Pepsi-Cola. O guaraná apresenta-se na segunda colocação no gosto dos consumidores, sendo que o guaraná Antarctica (da AmBev) encontra-se na primeira colocação nesse mercado. Nos últimos anos o guaraná Antártica vem sofrendo ameaça do Kuat da Coca-Cola, devido ao seu crescimento, impulsionado por campanhas publicitárias e pela qualidade semelhante ao guaraná da AmBev. Em seguida estão os sabores: laranja, limão, uva, e tônica. Destacam-se dentro desses sabores refrigerantes como Fanta Laranja e Uva, Sprite, Soda Limonada, Sukita entre outros.

\subsection{Material levantado}

\subsubsection{Levantamento das indústrias de refrigerantes:}

Foram encontradas mais de vinte pequenas e médias indústrias de refrigerantes espalhadas pelo Estado de São Paulo. Oito delas foram destacadas e analisadas mais detalhadamente. A partir do material coletado por visitas e entrevistas, foram feitas análises através das estratégias Genéricas de Porter e também das estratégias para atuação em mercados de baixa renda (5 categorias, 25 subcategorias).

O Quadro 2 apresenta as indústrias de refrigerantes encontradas no estado de São Paulo, e logo em seguida os casos que se destacam (dentre essas indústrias), marcas 
mais importantes e exemplos de boas práticas competitivas.

Quadro 2: Indústrias de Refrigerantes populares do Estado de São Paulo

\begin{tabular}{|l|l|}
\hline Empresa & Cidade \\
\hline Bebidas Mariotto Indústria e Comércio Ltda. & Taubaté \\
\hline Bebidas Vanucci S.A. Indústria e Comércio & Campinas \\
\hline CRBS Indústria de Refrigerantes Ltda. & São Paulo \\
\hline Dolly Refrigerantes & Diadema \\
\hline Ferráspari S.A. Indústria e Comércio de Bebidas & Jundiaí \\
\hline Fors Refrigerantes/Frankini Indústria e Comércio & Franca \\
\hline Indústria de Bebidas DON & Ribeirão Preto \\
\hline Indústria e Comércio de Bebidas Pivatto Ltda. & Cosmópolis \\
\hline Indústria e Comércio de Bebidas Furlan Ltda. & Cosmópolis \\
\hline Indústria e Comércio de Bebidas Ygarapés Ltda & Jacareí \\
\hline José C. Galvão César Ltda. & Guaratinguetá \\
\hline Peg Mais Indústria e Comércio Ltda & São Paulo \\
\hline Refrescos do Brasil S/A. & São Paulo \\
\hline Refrigerantes Arco Íris Ltda. & São José do Rio Preto \\
\hline Refrigerantes Convenção & Itu/Caieiras \\
\hline Refrigerantes de Santos S/A. & Santos \\
\hline Refrigerantes Maracanã Ltda. & Piracaia \\
\hline Refrigerantes Xereta & Itu \\
\hline Refriso & Sorocaba \\
\hline Spal Indústria Brasileira de Bebidas S/A & São Paulo \\
\hline Tuiubaina Vieira - Indústria e Comércio de Bebidas Vieira Rossi & Tatuí \\
\hline
\end{tabular}

Fonte: Resultados da Pesquisa. Elaborado pelos autores.

\subsubsection{1._ Fors Refrigerantes/Frankini}

\section{Indústria e Comércio}

Em 1928, Cezar Franchini começa a produzir refrigerantes, sendo que a Fors surge posteriormente, quando uma nova geração da família Franchini decide fabricar os produtos. Segundo o site da empresa, a Frankini/Fors tem como objetivo manter a liderança e a força que tem na região de Franca, sempre enaltecendo fatores como a tradição, qualidade de produtos e serviços, preços justos e tecnologia industrial. Os produtos da Fors são águas e refrigerantes (limão, cola, cola light, guaraná, guaraná light e laranja) em embalagens PET, de 2L, $510 \mathrm{ml}, 250 \mathrm{ml}$, e latas de $350 \mathrm{ml}$. Segundo matéria feita pelo jornal Comércio da Franca, em 2007, a Fors completava 5 anos, e tinha seus refrigerantes distribuídos em um raio de 150 quilômetros dentro dos Estados de São Paulo e Minas Gerais, estando presente em cerca de 80 cidades. Segundo o diretor industrial a Fors tem $40 \%$ de market-share regional (Franca). A marca está presente nos supermercados, 
bem como em lanchonetes, restaurantes e pizzarias por toda a cidade. Outro fator que chama a atenção é a gama de produtos razoavelmente ampla e a variedade de embalagens em que as bebidas são envasadas, já que fora as grandes marcas, poucas são as que têm recursos para vender refrigerantes em latas de alumínio.

\subsubsection{Refriso (Refrigerantes Sorocaba)}

Segundo o site da própria empresa, a Refriso é hoje uma das maiores empresas de bebidas da América Latina. Segundo seu site, "sua experiência em envase de bebidas carbonatadas proporciona um excelente produto final com custo extremamente competitivo. Além de uma ampla linha de produtos próprios, a estrutura da Refriso é preparada para atender empresas que desejam terceirizar sua produção." A empresa fabrica bebidas das seguintes marcas: Bacana, Vedete, Kiko, Cachoeira, Original e Red Night. As embalagens PET são fabricadas na própria empresa, bem como os rótulos e o empacotamento das bebidas. As embalagens variam de acordo com a marca e o produto. Há embalagens PET que vão de $350 \mathrm{ml}$ até 2 litros, e latas de $250 \mathrm{ml}$ e 350ml. A empresa possui uma E.T.E. (Estação de Tratamento de Efluentes) com eficiência de $98 \%$ no processo de remoção da DBO (Demanda Bioquímica de
Oxigênio). A Refriso possui diversas marcas populares de refrigerantes. São marcas semelhantes, mas que atuam em cidades diferentes, e, aparentemente, são mantidas até hoje pelo apelo que cada uma tem em seus mercados, pela tradição, ou por sabores únicos que as diferenciam.

\subsubsection{Refrigerantes Convenção}

A empresa foi fundada em 1951, na cidade de Itu, tendo começado como destilaria de bebidas alcoólicas. Mais tarde passou a produzir também refrigerantes. Em 1984 construiu uma nova fábrica na cidade do Rio de Janeiro, e em setembro de 1986 instalou-se também em Caieiras. Além dos refrigerantes Convenção (nos sabores Laranja, Laranja Light, Guaraná, Guaraná Light, Frutaína, Limão, Uva e Abacaxi), a empresa possui outras linhas de produtos, como Convenção Chá, Convenção Refresco, Convenção Xarope, e outras marcas também como os refrigerantes Vitt's, Guaraná Amazon, Chinotto, Hcon Lemon, ZeroCon e água Doce Vida. Chama a atenção essa ampla gama de produtos, e também o site da empresa na internet. Dentre todos os sites próprios encontrados, é um dos mais modernos e visualmente agradáveis, senão o mais. A marca Convenção é uma das mais tradicionais no interior de São Paulo, e isso se comprova pela presença da ampla 
linha de produtos da empresa em boa parte dos supermercados de cidades como Itu e Campinas. Outra prova do sucesso da empresa é o moderno website, que aparece como um mecanismo de se destacar das demais indústrias de refrigerantes populares.

\subsubsection{Ferráspari S.A. Indústria e} Comércio de Bebidas

A empresa surgiu na década de 1930, como produtora de vinhos, aguardentes, vermutes e xaropes, e produzia também balas com sabor de Turbaína. Com o tempo, a fabricação da bala foi extinta e se passou a produzir somente o refrigerante. A Ferraspari produz refrigerantes em sete diferentes sabores (Turbaína, Laranja, Limão, Uva, Abacaxi, Guaraná e o novo Guaraná com pêssego) e em várias embalagens. Além disto, fabrica quatro sabores de xarope da marca Tropical: groselha, morango, uva e guaraná. Produz ainda, xaropes para as marcas Carrefour, Cereser e Aro (Makro Atacadista). A marca tem destaque e é importante para o estudo porque é a criadora e detentora do nome "tubaína". Apesar de ainda ser uma empresa relativamente pequena, sobrevive ainda nos dias de hoje.

\subsubsection{Refrigerantes Arco Íris Ltda.}

Segundo o website da empresa, em $1^{\circ}$ de Julho de 1958, foi fundada a Mattos e Cia, na cidade de Tanabi-SP, que fabricava os refrigerantes Cotuba e Guri, além da aguardente da marca ARARA. A empresa abriu uma nova unidade em São José do Rio Preto, e iniciou suas atividades no ano de 1972, produzindo exclusivamente refrigerantes (Cotuba e demais sabores), ficando a unidade de Tanabi com a produção de produtos alcoólicos. Neste mesmo ano a empresa Mattos \& Cia adquiriu a fábrica detentora da marca Arco Íris da cidade de São José do Rio Preto SP, cujo refrigerante passou a ser produzido nesta nova unidade.

A empresa possui diversos produtos, sendo os refrigerantes fabricados sob os nomes Arco Íris, Cotuoba (Guaraná), Orangete (laranja), Ski Cola e Zip Cola. Os sabores de refrigerantes são Cola, Guaraná, Laranja, Uva e Limão. Além disso, são produzidos também destilados, água, água tônica, vinagre, Ice sucos. A marca tem atuação sólida na região de São José do Rio Preto. Apesar da distância da capital paulista, o que poderia dificultar uma possível visita, o caso é interessante pelo apelo popular que a marca tem na região, e também pelo fato de a marca exportar seus produtos. Foi uma das empresas com as 
quais foi possível estabelecer contato e, mais do que isso, fazer uma visita e entrevistar seu diretor de operações.

\subsubsection{Refrigerantes Xereta}

A marca foi fundada por Antonio Romano Schincariol, da mesma família dos fundadores da Schincariol, tradicional marca de bebidas brasileira, na década de 1970. A tradição da família na produção de bebidas certamente influenciou no sucesso da marca, que hoje tem capacidade de produção de 35 milhões de litros por mês e exporta para EUA, Japão, Austrália e Mercosul. A empresa possui diversas marcas, sendo a principal delas a Xereta. Além de refrigerantes, há também sucos em pó, groselha e barras de cereais com o nome da marca. Além dos produtos Xereta, a empresa também tem outras marcas, como a Vittal (que produz chá preto, sucos em lata, refrigerantes de guaraná e limão de baixa caloria) e Good Coco (coco ralado). Além disso a empresa também terceiriza o envase para outras empresas menores, e produz refrigerantes de marca própria de grandes varejistas, como Walmart e Carrefour. Em se tratando das empresas que fabricam "tubaínas", a Xereta é uma das que mais cresceram nos últimos tempos, tendo investido fortemente em marketing. O destaque que a marca teve nos últimos tempos, sobretudo no final da década de 1990, faz com que seja extremamente válido estudar as estratégias adotadas pela empresa para sobreviver e incomodar as grandes empresas do setor.

\subsubsection{Indústria de bebidas DON}

A empresa foi fundada em 20 de novembro de 1964 , e é uma das marcas mais famosa dentre os refrigerantes populares na região de Ribeirão Preto. Seu produto mais famoso é o refrigerante de maçã, uma das bandeiras mais famosas da marca. A Don tem distribuidores nas cidades de Ribeirão Preto, Franca, Bebedouro, Barretos, São Carlos e Araraquara. É a marca regional mais consagrada na região de Ribeirão Preto. É a mais conhecida e lembrada dentre as marcas com atuação regional, e também a mais consumida.

\subsubsection{Dolly Refrigerantes}

A Dolly é hoje umas das maiores e mais conhecidas dentre as indústrias de "tubaína" da região Sudeste. A empresa surgiu em 1987, e destaca-se por ser a primeira empresa brasileira do ramo a ter produzido bebidas dietéticas. Além disso, a Dolly tornou-se famosa por seus comerciais televisivos, exibidos na TV Gazeta e na RedeTV, e pelo escândalo no qual se envolveu com a Coca-Cola. Em relação a esse acontecimento, há materiais 
de áudio e vídeo no site da própria empresa, que comprovam que o então presidente da Dolly sofreu ameaças de morte de um ex-funcionário da Coca-Cola. É provável que o sucesso da empresa de certa forma incomodava as empresas maiores, tendo em vista este ocorrido. Outro ponto que chama a atenção é que a empresa investe bastante em propaganda e marketing. Além dos materiais publicitários divulgados na TV, a empresa patrocina eventos, com destaque para a Stock Car.

\subsection{Confronto dos resultados com a teoria}

\subsubsection{Estratégias genéricas de Porter}

Porter (1986 e 1990) afirma que é necessário seguir uma dentre as três estratégias genéricas (liderança por custos, diferenciação e foco) para que uma empresa tenha uma vantagem competitiva e, conseqüentemente, alcance o sucesso. A partir do material coletado, fica evidente que, dentre as três estratégias genéricas, as indústrias populares analisadas priorizam, no geral, o foco nas regiões em que atuam. As três empresas que de fato participaram da pesquisa (respondendo aos questionários ou entrevista) optam por atender aos desejos de uma pequena parcela do mercado de refrigerantes brasileiro, que é o mercado regional em que essas empresas se inserem.

Essas empresas exploram muito o fator cultural que está enraizado no consumo desses refrigerantes regionais. Além do hábito passado de pai para filho, outros fatores contribuem para o sucesso dessas marcas regionais. Como geralmente são prósperas, essas empresas - que são nascidas nas regiões em que se localizam geram empregos e são tratadas como um patrimônio, um orgulho para a região. Aliando todos esses fatores a um padrão de qualidade que tem como benchmark as grandes empresas, esses pequenos e médios produtores conseguem estabelecer preços para seus produtos que levam a um aumento da disposição a pagar de seus consumidores.

Dessa forma, os preços desses refrigerantes populares regionais costumam ser menores que o das grandes marcas, mas elas conseguem explorar preços maiores que o de refrigerantes populares de qualidade inferior, visto que há fatores culturais que influenciam seu consumo. Por outro lado, o fato de os preços serem maiores que de outros refrigerantes populares é um fator que impede que essas empresas se consolidem em mercados onde não há a tradição cultural de se consumir seus produtos, e também nos grandes centros onde a 
concorrência é maior. Por esse motivo elas focam suas vendas nas regiões em que se localizam, e muitas não têm interesse de se expandir para outras áreas, nas quais não conseguiriam manter a margem de lucro que elas têm em suas regiões.

\subsubsection{Estratégias para atuação em} mercados de baixa renda

Segundo a sistematização feita por Zancul (2005), muitas das estratégias divididas nas 5 categorias e 25 subcategorias são utilizadas, mesmo que possivelmente isso seja feito sem saber que existe uma teoria que aborda essas estratégias, e mesmo que por vezes isso possa ser feito de maneira informal.

Em relação à primeira categoria (modelo de negócios para mercados de baixa renda), pode-se dizer que a Refrigerantes Arco-Íris utiliza-se da verticalização para reduzir custos (com a produção de garrafas PET na própria empresa) e também para viabilizar a entrega aos diversos e espalhados clientes (com sua frota própria de veículos). Além da Arco-Íris, muitas outras pequenas e médias empresas (como a Refriso e a Convenção) também produzem suas próprias embalagens PET, pois isso se tornou um fator primordial para ser competitivo nesse mercado, visto que a custo de produção das garrafas PET representam $40 \%$ do custo total.

Outra prática importante e comum que as empresas analisadas adotam é a produção para terceiros, que as ajudam a obter ganhos de escala. A Xereta, por exemplo, envasa os refrigerantes de marca própria de Wal-mart e Carrefour. A ArcoÍris foi durante 10 anos envasadora dos refrigerantes Brahma, e posteriormente da Schweppes, o que lhe conferiu know-how a respeito das práticas adotadas pelas grandes empresas do mercado de refrigerantes. Hoje a Arco-Íris inova, e produz refrigerantes de marca própria para cerca de vinte supermercados de menor porte na região de São José do Rio Preto. Além disso, outra prática comum é o foco em redução de custos, visível a partir da estrutura organizacional enxuta que se tem, por exemplo, na Refrigerantes Convenção e na Refrigerantes Arco-Íris.

Em relação à segunda categoria (Processo de desenvolvimento de produtos populares), pode-se dizer que as pequenas e médias empresas atuam como fast followers (seguidores rápidos), que seguem as tendências e as práticas de sucesso adotadas pelas grandes empresas. A implementação das garrafas PET é uma prova disso, já que foi introduzida por uma das grandes marcas, e rapidamente foi adotada por empresas como a 
Refrigerantes Convenção e a Refrigerantes Arco-Íris. Segundo a entrevista feita com o diretor da Arco-Íris, a empresa procura seguir o padrão das práticas de sucesso da Coca-Cola.

A terceira categoria (Características dos produtos populares) também tem subcategorias que se encaixam ao mercado de refrigerantes populares regionais. A inovação em embalagens é um aspecto importante para se diferenciar no mercado de refrigerantes e também para reduzir custos. A Fors possui uma das maiores gamas de embalagens utilizadas, sendo uma das poucas dentre as médias e pequenas empresas de refrigerantes que utilizam latas de alumínio, e a Convenção reduziu o peso de suas embalagens para diminuir custos. Além disso, a alta qualidade é um ponto que algumas das empresas regionais analisadas procuram atender, tais como a Arco-Íris e a Refrigerantes Don.

$\mathrm{Na}$ quarta categoria (Processos de produção), o cabe ressaltar a presença de equipamentos modernos e de alta tecnologia no mercado de refrigerantes populares. Empresas como a Convenção e a Arco-Íris possuem equipamentos de última geração, semelhantes aos utilizados por empresas líderes no Brasil e no mundo.

Em relação à quinta categoria (Processos de vendas, distribuição e pós- venda de produtos populares), há uma subcategoria fundamental para esse estudo, que se encaixa perfeitamente ao mercado de refrigerantes populares. É a subcategoria que trata da distribuição em mercados específicos (regiões ou cidades), que é exatamente o foco que as pequenas e médias indústrias de refrigerante procuram adotar, visto que seu produto se adéqua (devido a questões culturais) às necessidades dos consumidores. Refrigerantes como o Don, Arco-Íris, Fors e Ferráspari focam suas forças de venda em suas regiões, nas quais atingem números significativos de vendas, faturamento e participação de mercado. Muitas dessas empresas nem sequer possuem interesse em expandir suas ações, por saberem que seu sucesso se deve em grande parte ao componente cultural intrínseco ao seu consumo.

Outra subcategoria que se encaixa a esse mercado é o uso de soluções logísticas alternativas. Para reduzir os custos de frete, a Arco-Íris possui uma frota própria com 60 caminhões e 60 carros, enquanto que a Convenção faz parcerias para reduzir as despesas com frete de retorno no transporte inter-plantas. Por fim, as pequenas e médias indústrias de refrigerantes também se utilizam de canais de venda alternativos com menor poder de barganha. Muitas vezes, as grandes redes varejistas 
pressionam para baixo as margens dos fornecedores, o que torna mais difícil negociar preços. Com os varejistas menores o poder de barganha dos fornecedores é maior, o que possibilita que se consiga melhores posições e maiores espaços em gôndolas e pontos extra em mercados, além de margens maiores de lucro, na medida em que se consiga negociar preços mais altos, devido ao menor volume negociado. Empresas como a Ferráspari, Arco-Íris e Convenção possuem um forte relacionamento com clientes de menor porte, como pequenos mercados, bares e restaurantes.

Frente ao crescimento das indústrias menores, houve um aumento do investimento por parte das grandes corporações - tanto em produção (inclusive com a aquisição de algumas marcas menores) quanto em marketing e publicidade - além do uso de artifícios como a compra de espaço em gôndolas de supermercados e contratos de exclusividade em pontos de venda estratégicos. É de se esperar que, com essa concorrência cada vez mais árdua, as pequenas e médias empresas tenham também tomado providências para novamente fazer frente e incomodar as grandes indústrias, fazendo com que seu crescimento fosse retomado em 2009.

\section{Conclusão}

A principal estratégia adotada pelas indústrias de tubaínas analisadas é priorizar a venda de seus produtos nas regiões em que se inserem. Um fator muito importante que essas empresas exploram é a identidade que os consumidores constroem com os refrigerantes locais. Nesse sentido, essas empresas trabalham muito no sentido de que se estabeleça uma cultura local de se consumir os refrigerantes da região. Como as empresas analisadas são antigas, essa cultura já existe, e o consumo de seus refrigerantes já faz parte dos hábitos da população de sua região, passa-se tal hábito de geração para geração, o que leva tais empresas a competir de frente com as grandes e a roubar destas uma parcela significativa do mercado local. Essas empresas são vistas como um patrimônio local, motivo de orgulho para a população, uma vez que geram empregos e passam uma imagem próspera e de sucesso.

Para se manter como concorrentes fortes nesses mercados locais, investem pesado em equipamentos modernos e de alta tecnologia, semelhantes aos utilizados pelas grandes empresas do setor. Embora se tenha uma imagem pejorativa da "tubaína" como um refrigerante de qualidade inferior, as empresas analisadas demonstram preocupação em investir 
sempre para oferecer aos seus clientes um produto de qualidade. Ficou claro que elas têm interesse em oferecer produtos de qualidade semelhante, mas com um preço menor que os preços dos refrigerantes das marcas maiores, sem ter que baixar abusivamente seus preços para conseguir ganhar mercado a qualquer custo. Por esse motivo, essas empresas se mantêm nas regiões em que surgem; nesses locais, os consumidores têm uma disposição maior a pagar pelos refrigerantes locais, com os quais eles possuem laços e aos quais eles associam uma imagem de tradição. Como a população local está habituada e consome muito os refrigerantes locais, os varejistas maiores também precisam vendê-los, o que resulta na possibilidade de se negociar espaços maiores e melhores nas gôndolas, pontos, extra, etc.

Isso não ocorre com as "tubaínas" que vêm de outras regiões, as quais precisam diminuir os preços para conseguir ganhar mercado. Da mesma forma o inverso é recíproco: as empresas analisadas focam a venda de sua produção nas áreas em que já são fortes porque não tem condições ou interesse em baixar seus preços para competir em mercados onde a concorrência será maior. Cada empresa tem suas próprias estratégias, as quais são estabelecidas de acordo com suas necessidades. Algumas optam, por exemplo, por utilizar frotas próprias de veículos, para conseguir atender a todos os clientes, enquanto que outros preferem terceirizar os fretes e fazer parcerias para reduzir os custos. Entretanto, é consenso entre as empresas mais competitivas que é preciso investir constantemente em inovação e seguir as tendências impostas pelos grandes players do mercado, para se manterem atualizadas, reduzir custos e serem competitivas. Uma tendência que se nota é a verticalização das etapas de produção. Muitas indústrias produzem suas próprias garrafas PET, por exemplo, desenvolvendo embalagens originais como forma de se diferenciar, e reduzindo seu peso para reduzir custos.

Outra estratégia utilizada para enfrentar as grandes indústrias de refrigerantes é produzir para terceiros, envasando bebidas para marcas próprias de redes de supermercados, ou mesmo para marcas maiores. Dessa forma, as pequenas e médias indústrias conseguem otimizar a ocupação de suas máquinas, e no caso de envasar refrigerantes para marcas maiores, conseguem manter contato com as práticas adotadas por essas marcas. Ademais, outra estratégia utilizada pelas indústrias locais é vender seus produtos em canais de vendas de menor porte, cujo poder de barganha costuma ser também menor, o que facilita 
a negociação de preços mais atraentes aos fabricantes.

Sugere-se que se continue a pesquisar nessa área, pois há muitas indústrias interessantes a serem exploradas no Estado de São Paulo e em outros Estados brasileiros. Futuras pesquisas na área poderiam abordar também as bebidas do tipo água saborizada ou flavorizada, que é a água mineral comum acrescida de sabor de frutas - normalmente limão, laranja ou morango. A água saborizada é composta apenas por água comum e sais minerais, conservantes, com a leve adição de aromatizante de frutas e adoçante (normalmente a sacarina sódica). Também pode haver a adição de gás carbônico à água, mas em quantidades muito menores que nos refrigerantes. Apesar de, no Brasil, a água saborizada ser definida pela ANVISA como refrigerante, é considerada uma alternativa saudável aos refrigerantes, muito apreciada por esportistas e adeptos de um estilo e vida mais saudável. A complementação dessa pesquisa com a análise de outras empresas traria informações riquíssimas para este estudo, e completariam de maneira muito valiosa essa pesquisa.

\section{Referências}

1. ABIR - Associação Brasileira da Indústria de Refrigerantes. http://www.abir.org.br

2. AFREBRAS - Associação dos Fabricantes de Bebidas do Brasil. http://www.afrebras.org.br

3. BARDIN, L. Análise de conteúdo. Lisboa: Edições 70, 1979. 229 p.

4. BLECHER, N. Máquina de Vender. Revista Exame. n. 811, 11 de fevereiro. 2004a

5. BLECHER, N. Gol, a empresa do ano. Revista Exame. n. 821, p.20-31, 7 de julho. 2004b.

6. BLECHER, N. \& TEICHEIRA, S. O Discreto Charme da Baixa Renda. Revista Exame. p. 36-48. 01/10/2003.

7. BONEL, E. \& ROCCO, E. Coopeting to survive; surviving coopetition. Int. Studies of Mkt. \& Org., vol. 37, no. 2, Summer 2007, pp. 70-96.

8. CORREA, Cristiane. Mãos de Tesoura. Revista Exame.São Paulo; edição 789, ano 37 no 7; ed.abril, p.44 - 52, abril 2003.

9. DRUCKER, Peter F. A corporação Sobreviverá. Revista Exame. São Paulo; edição 792, ano $37 \mathrm{n}^{\circ} 10$; ed. Abril, p. 100 - 106, maio 2003.

10. DRUCKER, Peter F. Desafios Gerenciais para, o século XXI. São Paulo: Pioneira, 2000.

11. FGV. Pesquisa sobre a pobreza. Rio de Janeiro. Doc. Interno / Unilever. 2003.

12. GARCEZ，M.P.; CARDOSO, M.V.; GUIMARAES, A.F. \& YU, A. Estratégia de Inovação em Produtos e Processos para a Obtenção de Liderança em Custos no Mercado Popular de Bebidas - o Caso da Refrigerantes Convenção. In: CONGRESSO LATINOAMERICANO DE ESTRATÉGIA, 17 $7^{\circ}$ Itapema, Anais. 2004.

13. GUIMARAES, A.F; GARCEZ, M.P \& CARDOSO, M. V. Inovando em produtos e processos no mercado popular de bebidas - $\mathrm{O}$ caso da 
Refrigerantes Convenção. Série de Working Papers - FEA/USP. São Paulo. 2003

14. Harvard Bus. Review. Exame. São Paulo; Ed. 779, ano 35 no 23; Abril, p. 94-100, Nov. 2002.

15. KOTLER, Philip. Marketing para o século XXI. São Paulo: Futura, 2000. $305 \mathrm{p}$.

16. LIMA, Andréa de. Jesus é líder entre guaranás no MA. Folha de São Paulo. 03/04/2000

17. MACHADO, A.G.C; OLIVEIRA, M.V.S.S \& FILHO, J.R.R.C. Frevo arretado: os duros passos no mercado de refrigerantes. XI SIMPEP, Bauru, SP. Nov. 2004.

18. MARGOLIS, M. Profit and the Poor: consumer-goods makers are realizing thy have only one direction to go for growth: down market. Newsweek, July 19, 2004. p. 36-38.

19. MARINO, M.K.; MIZUMOTO, F.M. \& PEREIRA, M.L.G. Inovação no Segmento de Produtos Populares: o caso da Scala na produção de massas. FEA-USP. 2003.

20. MARSON, A.B.; KLEMENT, C.F.F. \& ALMEIDA, L.F. $O$ Processo de Inovação na Industria Brasileira de Autopeças para Veículos Leves: Estudo Comparativo de Casos no Segmento de Reposição. São Paulo. FEA- USP. 2003.

21. MATTOS, A. Pequenos e médios fabricantes reclamam que as isenções fiscais da multinacional são "imorais e aéticas". Folha de São Paulo. 31/08/2000.

22. MIRANDA, Heráclito. Cada empresa deve perseguir fatores chave de sucesso, que criem diferenciais competitivos. Revista Economia. Estado de Minas. 01/03/2001.

23. MORAIS, Jomar. Frevo arretado. Exame. 02/06/1999. Disponível em http://www.planetajota.jor.br/tubaina.ht $\mathrm{m}$
24. NASCIMENTO, P.S.T. \& YU, A. S. O. Estratégias de Inovação Para Produtos de Consumo Popular. VI SEMEAD, Universidade de São Paulo. 2003.

25. NOGUEIRA, A.C.L.; SOUSA, W.H.; YU, A. \& REHDER, H. Gestão da Inovação e o Mercado de Produtos Populares: O Caso da Indústria de Sorvetes Alaska. 2003.

26. OESP Mídia. Leilão reverso é nova ferramenta de compras da CVI. AESetorial.com, 14/02/2003. Disponível em http://www.me.com.br/oesp/PorDentro 1.asp? Noticia $=1943$

27. O doce sabor da tubaína - Istoé. http://www.terra.com.br/istoe/economi a/151231.htm

28. PANORAMA Setorial. A Indústria de Refrigerantes e Água. Gazeta Mercantil. São Paulo, 1998. Acesso em 04/12/2003.

29. PINSKI, I; FÁVERO, L.P.L. \& ONOYAMA, M.M. A Importância do Entendimento do Comportamento do Consumidor e do Desenvolvimento de Produtos como Estratégia de Atuação de Empresas de Cosméticos: o estudo de caso da L'oréal do Brasil. FEAUSP. 2004.

30. PORTER, Michael. Estratégia Competitiva. Técnicas para Análise das Indústrias e da Concorrência. Rio de Janeiro: Campus; 1986. 404p.

31. PORTER, Michael. Vantagem Competitiva. Criando e Sustentando um Desempenho Superior. Rio de Janeiro: Campus. 1990. 512p.

32. PRAHALAD, C. K. \& HART, S. L. The Fortune at the Bottom of the Pyramid. Strategy + Business, v. 26. 2002.

33. PRAHALAD, C. K. \& LIEBERTHAL, K. The End of Corporate Imperialism. Harvard Business Review, july-august, 1998. p.69-79.

34. RECALL. Tubaínas mudam de cara e já controlam $32 \%$ do mercado. Revista 
Recall. Edição 49. 2003. Disponível on-line

http://www.fonte.jor.br/pagina_indice.a $\mathrm{sp}$ ? Iditem $=149$

35. Refrigerantes Arco Íris Ltda. http://www.cotuba.com.br/html/index.h tm

36. SANTOS, S.R.S \& AZEVEDO, P.F. Concorrência no mercado de refrigerantes: impactos das novas embalagens. UFSCar. 2000.

37. TAYLOR, G.A. Estrat. de competição na indústria de bebidas. FAE Business, n.2, jun. 2002.

38. TORREÃO, Luciana. Lucros borbulhantes e refrescantes. N. 45, Julho/2003.

39. Tubaínas mudam de cara e já controlam $32 \%$ do mercado. http://www.easysite.com.br/fontejor/pa gina_indice.asp?iditem $=149$

40. UNILEVER (2009) http://www.unilever.com.br/marcas/ . Acesso em 5 de maio de 2009.

41. VERGARA, S. C. Projetos $e$ Relatórios de Pesq. em Administração. São Paulo: Atlas, 1998.

42. WOLBURG, J.M. Colas big and little: anti-trust laws, non-regulation and the disabled marketing of small brands. Journal of Consumer Marketing, V.20, N. 5, 2003, pp.397-399.

43. YIN, R. Estudo de caso: Planejamento e Métodos. Porto Alegre: Bookman, 2001.

ZANCUL, E. S. Inovações no modelo de negócios, processos e produtos para atuação em mercados de baixa renda. XXV Encontro Nac. de Eng. de Produção. ENEGEP. Porto Alegre. 2005. 